Deadline for abstract submission is June 17, 2019.

\title{
Dynamic Modeling: The influence of the Improved Solid Elutriation Correlation on the Two-Phase Mathematical Model of Polyolefin Polymerization in Gas-Phase Fluidized Bed Reactor
}

\author{
Mohd Farid Atan ${ }^{1,2 *}$, Mohd Azlan Hussain² \\ ${ }^{1}$ Department of Chemical Engineering and Energy Sustainability, Faculty of Engineering, Universiti \\ Malaysia Sarawak, 94300, Kota Samarahan, Malaysia \\ ${ }^{2}$ Department of Chemical Engineering, Faculty of Engineering, University of Malaya, 56000, Kuala \\ Lumpur, Malaysia \\ *e-mail: amfarid@unimas.my
}

\begin{abstract}
Process modeling plays an important role in improving and intensifying the chemical process especially the polymerization process with the main aim to improve the operating conditions as well as achieving the quality of the desired polyolefin. The mechanism to build, construct and simulate the polymerization process is relatively complex due to its high non-linearity of process dynamics. This non-linearity is induced by several aspects such as the reaction mechanism, the heat, and mass transfer mechanism, the flow properties in both solid and gas phase, the type of the reactor used for the polymerization process, and the correlations between the operating conditions with the chemical and physical properties of the produced polyolefin. In this study, polypropylene is chosen as a case study, and the reactor used is a fluidized bed reactor (FBR). This fluidized bed reactor is chosen due to its capability in carrying several type chemical reactions and it possesses very good particle mixing as well as a high rate of heat and mass transfer. In addition, this study is focusing on improving the solid elutriation correlations proposed previously with the aim of increasing the reliability and the accuracy of this two-phase model. The influence of the composition of the reactants injected in the reactor, the inlet temperature and the catalyst flow rate with the production rate are studied and analyzed. The main finding demonstrates that by embedding the improved solid elutriation correlation, it reduces the production rate compared to other proposed solid elutriation correlations implemented previously due to the loss of the product at the top of the fluidized bed reactor. Lastly, the composition of the reactants and the catalyst flow rate have an influence on the production rate. However, the inlet temperature does not have any influence on the production rate.
\end{abstract}

Keywords: Mathematical modeling; Polyolefin; Fluidized bed reactor; Solid elutriation

\section{References}

Salahuddin, N.F., Shamiri, A., Hussain, M.A., Mostoufi, N. Fuzzy-GMC Control of Gas-Phase Propylene Copolymerization in Fluidized Bed Reactor. In Proceedings of the 24th Regional Symposium on Chemical Engineering (RSCE 2017), Semarang, Indonesia, 15-16 November 2017

Abbasi, M.R., Shamiri, A., Hussain, M.A. Dynamic modeling and Molecular Weight Distribution of ethylene copolymerization in an industrial gas-phase Fluidized-Bed Reactor. Adv. Powder Technol. 2016, 27, 1526-1538

Shamiri, A., Hussain, M.A., Mjalli, F.S., Mostoufi, N., Shafeeyan, M.S. Dynamic modeling of gas phase propylene homopolymerization in fluidized bed reactors. Chem. Eng. Sci. 2011, 66, 1189-1199. 